\title{
Novas tecnologias na ótica do discurso promocional televisual ${ }^{1}$
}

NEW TECHNOLOGIES IN PROMOTIONAL TELEVISUAL DISCOURSE

\section{Maria Lilia Dias de Castro}

Docente do Programa de Mestrado em Ciências da Comunicação da UFSM da Universidade

Federal de Santa Maria.

E-mail: mlilia@terra.com.br

Recebido em 9 de agosto de 2015. Aprovado em 23 de novembro de 2015.

\section{Resumo}

Nos dias de hoje, a televisão brasileira, além do seu caráter privado e, assim, da necessidade de obediência às restrições do mercado, vem convivendo com o alucinante crescimento tecnológico, o que significa repensar completamente seus fazeres e até dividir sua audiência com telefones, tablets, computadores. Nesse sentido, o objetivo do presente trabalho é investigar as relações entre essa mídia e os novos aparatos tecnológicos disponibilizados, analisando seus efeitos na especificidade da produção discursiva televisual, sobretudo aquela de caráter promocional. Para tanto, discute as propriedades da televisão no país, a influência dos fatores econômicos e tecnológicos na produção discursiva e busca examinar esses traços em um programa da emissora (a telenovela Sete vidas).

Palavras-chave: Televisão privada. Economicismo e tecnologismo. Produção discursiva. Expansão e condensação. Promocionalidade.

1 Trabalho apresentado no VI Pró-Pesq PP - Encontro de Pesquisadores em Publicidade e Propaganda, de 27 a 29/05/2005, CRP/ECA/USP. 


\section{Abstract}

These days, Brazilian television, besides its private character and thus the need to submit to the restrictions of the market, has been living with fast technological growth, which means completely rethinking their duties and even share its audience time with phones, tablets, computers. In this sense, the objective of this study is to investigate the relationship between this media and the new technological devices available, analyzing their effects on specificity of televisual discourse production, especially that of promotional nature. Therefore, discusses the properties of the television in the country, the influence of economic and technological factors in the discursive production and seeks to examine these traces in a station's program (television series Sete vidas).

Keywords: Televisual media. Promotional discourse. New technologies. Discursive production. Expantion and condensation.

\section{Considerações preliminares}

O surgimento da televisão no continente europeu, na década de 1950, representou, inequivocamente, uma verdadeira revolução na comunicação, sobretudo pela incorporação da imagem, que sempre auxiliou o telespectador a melhor compreender o mundo a sua volta, outorgando a essa mídia a inigualável condição de janela para o mundo. A exploração da imagem permitiu ainda o acesso mais fácil a novas realidades, transformando a televisão, como bem ressalta Wolton, em um dos principais instrumentos de comunicação, tanto pelas informações que traz como pela possibilidade de proporcionar que as pessoas falem sobre isso, estimulando a conversação.

Além disso, por ser acessível a todos, gratuita e com um leque de mensagens de todas as naturezas, a televisão desde sempre se constituiu como natural instrumento de emancipação, possibilitando, para a sociedade como um todo, avanços significativos no plano social, cultural e político.

Nesse percurso, a televisão, impulsionada pelos avanços tecnológicos e pela ameaça das novas plataformas que chegaram para subverter as lógicas entre produtores e receptores, foi-se voltando menos para os fatos externos, os acontecimentos do mundo, e mais para o próprio fazer, a fala de si - o que ocasionou a predominância de discursos voltados à divulgação desse fazer e/ou à projeção da emissora no cenário da comunicação no país.

Todo esse panorama suscitou indagações de diferentes ordens: como tem sido o comportamento da mídia televisual ante as novas plataformas digitais? Como a televisão tem-se valido dos avanços de ordem técnica para aprimorar seus discursos? Como se caracterizam os discursos televisuais com as novas ofertas? Que mudanças são operadas 
no que se refere aos discursos empregados? Como as tecnologias interferem na produção discursiva?

Diante dessas indagações, o objetivo do presente trabalho é, a partir da relação entre mídia televisual e avanços tecnológicos, investigar os efeitos da tecnologia no discurso da promocionalidade e analisar suas especificidades. Para tanto, propõe-se a ressaltar as propriedades da televisão predominante no país, a influência dos traços econômicos e tecnológicos, a relação entre tecnologia e discurso televisual, e o exame dessas repercussões em um programa da emissora.

\section{Propriedades da televisão no país}

Desde o lançamento da televisão, no período pós-guerra, houve consenso no sentido de aceitar que o controle dessa mídia fosse exercido pelo poder público, para evitar que ela trouxesse prejuízo às pessoas, como fizera o rádio; e também convicção de que, assim configurada, a televisão poderia tornar-se instrumento determinante de democratização cultural. Diante dessa realidade, a televisão europeia foi marcada pelo vínculo ideológico com o Estado, pela adoção do compromisso de informar, entreter e educar, atrelado à responsabilidade pública, pela decorrente preocupação de oferecimento de programas educativos e populares e pela recusa à publicidade comercial.

Embora exitosa como mídia, seu atrelamento à política e ao Estado nem sempre conseguiu garantir o sucesso do modelo, e, nas décadas de 1980 e 1990, assistiu-se ao predomínio quase incondicional da televisão privada. Ao Estado restou a posição de parcialidade, o que redundou na aproximação mais estreita com os interesses dominantes e no estímulo ao oligopólio dos mercados. Aliás, essa nova condição fascinou os dirigentes empresariais por encontrarem nela um espaço de influência e projeção.

Mesmo assim, apesar da aparente oposição ao modelo então vigente, a televisão privada manteve as mesmas missões da pública: "mesma obsessão de audiência; mesma redução da diversidade da programação; mesma diminuição de documentários científicos, culturais e sociais; mesmo aumento da dimensão de 'espetáculo' na política..." (WOLTON, 2006, p. 30), pois acreditava que, assim, poderia transformar-se em sinônimo de liberdade e de progresso.

Todo esse processo de liberalização realizado exigiu da televisão a missão e a necessidade de sustentação do negócio, ou seja, o desafio de garantir, em termos financeiros, a própria manutenção e a consequente sujeição às leis do mercado. $\mathrm{O}$ resultado foi uma televisão supostamente voltada à informação, ao entretenimento e à educação, mas, essencialmente, regida pelo viés econômico, que se transformou em elemento 
constituinte e determinante. É como se tudo, a política da saúde, da educação, dos transportes, do gerenciamento do território e do meio ambiente fosse abandonado à lei única do mercado.

Assim, a televisão, além de veículo de comunicação, assumiu a condição de empresa, centrada em ações que lhe tragam retorno financeiro que, para ela, se traduz em qualificação da oferta e em disputa de audiência. E a meta da televisão, em um verdadeiro círculo vicioso, é quanto mais audiência, mais público; quanto mais público, mais atrativo ao anunciante para lançar produtos e/ou serviços; quanto mais anunciantes, mais ações de patrocínio e mais lucro à empresa.

Também no Brasil a iniciativa privada foi contaminada pela política de concentração de poder, acarretando o surgimento dos grandes conglomerados de mídia, responsáveis, inclusive, por expressivas transformações em todos os segmentos da vida das pessoas: família, trabalho, lazer, ambiente urbano. Essa influência ganhou tal proporção no país que rendeu à televisão de canal aberto algumas peculiaridades: (1) converteu-se em principal e quase único instrumento de informação, cultura e divertimento para parte significativa da população; (2) valeu-se das novas empresas que surgiram, ampliando o mercado consumidor e de anunciantes; (3) e, apesar de estabelecer eventuais acordos com empresas internacionais, manteve capital genuinamente nacional, representado pelas quatro grandes redes (Globo, Record, SBT e Bandeirantes), com destaque maior para a Rede Globo de Televisão, que comanda esse mercado.

\section{Natureza economicista e tecnologicista}

No quadro atual da televisão aberta brasileira há um predomínio absoluto da iniciativa privada, o que confunde sobremaneira a missão de entretenimento com a manutenção do negócio. Para mascarar essa condição, a televisão tem-se desdobrado entre dois discursos predominantes: o econômico, para o qual o mercado continua a ser o melhor princípio de regulagem, e o tecnológico, que está sempre prometendo revoluções e mudanças. E é esse duplo discurso que tem direcionado as políticas das empresas de comunicação.

Em relação ao paradigma econômico, Wolton indica duas direções assumidas pela mídia televisual: (a) na condição de empresa, tem-se submetido às demandas mercadológicas, como fusões, concentração, falências, alianças e conquistas de mercado; (b) na obediência às leis do mercado, tem enfrentado preços reais, veto aos produtos que não vão ao encontro do público, lucro, recurso à publicidade, um mínimo de rentabilidade (WOLTON, 2006, p. 36). 
Esse foi o caso do Brasil quando assistiu ao desenvolvimento de grandes corporações de mídia, de caráter privado, que, além de reunirem conglomerados formados por inúmeros segmentos de informação no país, constituem espaços de poder no comando do sistema comunicacional.

Nessa medida, para sobreviver, a televisão é obrigada continuamente a disputar audiência com as concorrentes, fazendo dos lares brasileiros um local de excelência para a exposição de suas realizações: desde diversidade de ofertas, participação em ações sociais junto à comunidade de atuação, incentivo a novas práticas e hábitos culturais - que ratificam a projeção de cada instituição no desafiante mercado da comunicação -, até inovações na grade de programação. E tudo isso é feito com o objetivo de atrair um público mais diverso, em uma dinâmica que busca harmonizar-se com a rotina das pessoas.

É dentro desse horizonte que se consolida a produção televisual brasileira, marcada, no mais das vezes, por uma função que lhe é inerente: a função promocional, ligada ao interesse econômico e manifestada sob a forma de textos.

Assim, além de sobredeterminar as demais funções, tradicionalmente atribuídas à televisão - informação, entretenimento, educação -, a promocionalidade facilita a ação do anunciante externo, na busca de espaço para publicizar produtos, marcas, serviços (exibições em espaços intervalares, atuação em patrocínios ou inserções comerciais e sociais no interior dos programas), e, ainda, serve de palco para o anunciante interno - a emissora - divulgar os próprios fazeres, exibir avanços tecnológicos, explicitar sua atuação no meio social, fazer sucessivas remissões a seus programas através de bandeiras sociais defendidas pela emissora, espaços socioeducativos de orientação à população, chamadas constantes à própria programação, dentro ou fora dos programas, entre outros.

É tão forte essa condição e está de tal forma impregnada no fazer televisual que se chega, muitas vezes, a reconhecer um viés de tendência economicista que contamina toda e qualquer ação e/ou produção em televisão. Isso favorece, naturalmente, o aumento da produção de caráter promocional: é preciso assegurar boa audiência para atrair anunciantes externos e, também, alardear ao público as contribuições trazidas pela emissora em benefício da sociedade, mobilizando saberes e valores responsáveis pelo incremento do consumo como condição de inserção social e de condição de um mundo melhor.

Outra peculiaridade é que, diferentemente das demais, que se voltam predominantemente para a satisfação do receptor, a função promocional atende igualmente aos sujeitos da produção e da recepção. Sendo assim, ela tanto se volta para o receptor, com a finalidade de informá-lo, entretê-lo ou educá-lo, como também, e sobretudo, torna-se espaço de exposição e qualificação de seu produtor (emissora ou empresa). Aliás, o movimento de prestigiar algo acaba frequentemente transformando-se em projeção da própria 
empresa, que também se vale desse discurso para falar de si mesma, configurando aquilo que se denomina de autopromocionalidade.

Essa reiterada fala de si, feita pela televisão, caracteriza aquilo que Eco denomina de neotevê, pois é uma televisão que, cada vez mais, fala sempre menos do mundo exterior. "Ela fala de si mesma e do contato que estabelece com o próprio público" (ECO, 1984, p. 182). Assim, ante a permanente e acirrada concorrência entre as emissoras e ao poder do telespectador de prontamente mudar de canal, a televisão vê-se obrigada a anunciar que está ali diante dele, que ela é a melhor maravilha, que ela tem as melhores informações, que ela quer contato com o público, criando todo um "circo" de atrações para falar de si.

Todo esse panorama leva Eco a recuperar uma antiga definição de televisão para definir com mais clareza o estado atual em que se encontra: "uma janela aberta sobre um mundo fechado" (ECO, 1984, p. 200), pelo fato de priorizar o próprio interior.

Em relação ao avanço tecnológico, não se pensa mais em televisão desvinculada de um processo que lhe empresta múltiplas atribuições: seja na qualificação da imagem, seja no aprimoramento dos sistemas de transmissão, seja na inserção das mídias digitais em produções televisuais, seja no desdobramento de suas temáticas para outras plataformas, o que permite que muitos nela reconheçam uma tendência de caráter tecnologicista.

Essa confluência de novas mídias caracteriza o fenômeno da convergência, entendida por Jenkins como o fluxo de conteúdos por meio de distintas plataformas (JENKINS, 2009), o que tem implicado a recorrência "a um conjunto de dispositivos e suportes tecnológicos advindos de outras mídias (ou plataformas), mobilizados para a realização, veiculação e consumo dos programas televisuais" (DUARTE; CASTRO, 2010, p. 14). Esse fenômeno acaba atingindo tanto os meios, na forma não linear de apresentação e exposição de conteúdos, como os próprios consumidores das mídias, na forma não sequencial como passam a acessar os conteúdos. A televisão busca incorporar cada inovação, trazida pelos tempos atuais, a fim de acompanhar avanços e usufruir benefícios.

Em linhas gerais, é como se os conglomerados de comunicação, hoje, buscassem controlar toda uma indústria de entretenimento, mostrando que "os antigos limites entre mídia, suporte e conteúdo tornam-se difusos e confusos e neles imagem, texto e áudio não apenas trafegam juntos, como se completam entregando ao usuário um conteúdo multimídia" (PATRIOTA, 2000, p. 115).

A decorrência natural de toda essa inovação, ou dessa meta tecnologicista, presentifica-se na popularização dos sites de redes sociais, na liberdade de expressão e circulação de informações na rede, na simplificação das ferramentas de produção e no quase apagamento das fronteiras entre produção e consumo (PRIMO, 2010).

\footnotetext{
$40 \frac{\text { Comunicação \& Inovação, PPGCOM/USCS }}{\text { v. 17, n. 33 (35-50) jan-abr } 2016}$
} 
Além disso, também se reconhecem novos desafios a produtores e receptores, na medida em que são incentivados a procurar outras informações e a fazer conexões com o uso de mídias dispersas. O receptor é convidado a assumir seu papel de protagonista e a tentar as múltiplas possibilidades de acesso. Essa nova realidade, à disposição dos consumidores, tem gerado um inusitado fluxo de conteúdos, um conjunto variado de manifestações e diversificados recursos de exibição.

Assim, pode-se dizer que a convergência abre "possibilidades para novos modos de interação com os receptores que, pouco a pouco, vão deixando a condição de meros telespectadores para se tornarem usuários e produtores" (DUARTE; CASTRO, 2010, p. 14).

Dessa forma, a cada dia que passa a mídia televisual está enormemente marcada por um movimento reconhecido pelo caráter predominantemente economicista e tecnologicista. Isso acarreta novas formas de interatividade que, então, interferem na recepção das informações, modificam a maneira de as pessoas agirem, pensarem e se relacionarem com a comunidade e com o meio e reestruturam as relações interpessoais de toda a sociedade, para mostrar, por fim, o quanto a convergência deve ser pensada, também, em termos culturais.

\section{Discurso de caráter convergente: expansão e condensação}

A abertura proporcionada pela convergência e a consequente transmidiação é pontual e inovadora, e aponta diferentes direções para a reflexão em torno da mídia televisual. Normalmente a discussão em torno da convergência leva a questões de ordem conjuntural ou a indagações referentes às repercussões dos padrões digitais na veiculação e consumo da mídia televisual, o que, muitas vezes, representa um abandono da investigação em termos de linguagem. Por isso, no âmbito deste trabalho, a reflexão centra-se no fenômeno da convergência, na perspectiva de um diálogo estabelecido entre as teorias do discurso e os avanços tecnológicos, estreitando os laços entre discursividade e tecnologia.

Até porque, como bem assinala Médola, "sob a égide da convergência, a linguagem televisual passa a integrar agora um sistema de comunicação marcado pela interoperabilidade entre os dispositivos digitais e, portanto, condição para um cruzamento de mídias e de conteúdos com o hibridismo dos formatos" (MÉDOLA, 2009, p. 248). São movimentos que deixam marcas no discurso, materializando-se em formatos diversos e diferenciados.

A interconexão entre a televisão e as novas tecnologias de comunicação, cabo, satélite e televisão de alta definição, não parou de crescer, convertendo os espaços da internet em verdadeiras extensões de programas. Hoje praticamente inexistem produtos 
televisuais que não experimentem o online, originando, com isso, todo tipo de extensões institucionais ou particulares: sites, blogs, twitters, portais, entre outros. "Tudo tem validade se atrair o telespectador/internauta para essa gama infinita de paratextos constituídos pelas modernas narrativas transmidiáticas" (DUARTE; CASTRO, 2010, p. 16).

Levando em conta o estado atual de desenvolvimento das novas tecnologias e examinando a convergência como uma sobredeterminação do texto televisual, podem-se reconhecer dois movimentos narrativos predominantes nas produções veiculadas por essa mídia: a condensação, relativa à concentração interna de texto e plataforma, e a expansão, referente ao transbordamento do texto para outras mídias ou plataformas. Assim, na interação que se estabelece entre texto televisual e outras plataformas, esses movimentos mostram-se sob duas variantes: a inerência, que põe em jogo a condensação, que diz respeito à interiorização da articulação entre o produto e a(s) plataforma(s) apropriada(s), nos limites do texto televisual; a aderência, que põe em jogo a exteriorização da articulação entre o produto e as plataformas apropriadas e está relacionada aos transbordamentos dos limites do texto televisual em direção a outras mídias.

Entre as formas de inerência podem-se ressaltar as seguintes possibilidades: (1) simples transposição de conteúdo de uma mídia a outra, como, por exemplo, a da tira de jornal "Aventura da família Brasil", convertida em narrativa televisual com mesmo nome; (2) convocação de outras mídias para tomarem parte no relato, como, por exemplo, o da internet, na telenovela Viver a vida, com função explícita na própria narrativa; (3) inserção de mídias que possibilitam a interferência do receptor no desenrolar da trama, como, por exemplo, a atuação do telespectador, via telefonia ou internet, no interior dos programas (DUARTE; CASTRO, 2010, p. 17), como é o caso de Big Brother, SuperStar, The Voice Brasil, entre outros.

A aderência decorre da expansão do texto televisual para outras plataformas e/ ou outras mídias, como por exemplo, jornais, revistas, quadrinhos, internet, outras plataformas com seus blogs, twitters e outros. O objetivo é fornecer informações sobre determinado programa e/ou personagens sob o comando da instituição, ou para permitir a interferência do público de acordo com o engajamento dos telespectadores (DUARTE; CASTRO, 2010).

\section{Análise da emissão}

No âmbito deste trabalho, a convergência é pensada como diálogo entre as teorias do discurso e a tecnologia, para reconhecer as estratégias empregadas por uma produção televisual: quando convoca para seu interior outros programas da emissora ou da 
concorrência (inerência), ou quando desdobra a produção em outras mídias ou plataformas (aderência).

Na sequência, busca-se, em perspectiva paratextual, explicitar a situação da emissora no contexto atual e caracterizar o programa de humor Tá no ar: a TV na TV na sua grade; e, em perspectiva intra e intertextual, examinar alguns dados constitutivos do programa e sua relação com outras emissões, da própria emissora e, quando for o caso, da concorrência, para explicitar esses movimentos de inerência e aderência aí presentes.

\section{Nível paratextual: pano de fundo}

\section{a. Situação da emissora}

Em 2015, a Rede Globo está completando 50 anos de atividade e durante todo o ano tem reservado espaço exclusivo à celebração desse acontecimento: desde a criação de novos formatos, passando por adaptações e/ou alterações de programas antigos, até a mobilização de todos seus profissionais - atores, diretores, apresentadores - na divulgação dos feitos da emissora.

Só no mês de janeiro, foram veiculadas as primeiras inovações relativas à programação anual, compreendendo anúncios publicitários, filmes especiais (transformação de séries, minisséries e seriados em filmes e veiculação de série estadunidense); novos programas (em especial Planeta Extremo, a 15 a temporada do Big Brother Brasil e a minissérie Felizes para Sempre?); até novas telenovelas (Sete Vidas, às seis, e Babilônia, às nove).

Criado em 2014 e exibido inicialmente no formato de teaser, depois como anúncio e, por fim, como programa especial, Vem aí buscou ocupar o espaço na grade para divulgar os lançamentos e os projetos, bem como para firmar a marca da emissora e da empresa no ano do seu cinquentenário.

Entre essas produções, foram veiculados:

- anúncios publicitários sobre a programação

Em janeiro foi lançada a campanha relativa às realizações da emissora para o ano, sob o comando de Maurício Guimarães e Luciano Zuffo. Enormes telões receberam, ao fundo, imagens coloridas e específicas referentes aos quatro segmentos mais importantes da programação, para mostrar, através dos profissionais mais experientes, a fusão entre as realizações da emissora e as pessoas comuns. Foram criadas quatro peças, cada uma com uma cor predominante, para representar os segmentos mais importantes da emissora, assim especificados: o segmento informaçãa (em azul), com os jornalistas Sandra Annenberg, Caco Barcellos, Wiliam Bonner e Tadeu Schmidt, anunciou as novas atrações, como "reportagens especiais, investigações e grandes coberturas"; o segmento 
emoção (em vermelho), com os atores Cauã Reymond, Gloria Pires, Sophie Charlotte e Toni Ramos, mostrou que os dramas e romances a serem exibidos vão encher a vida de "lágrimas e risadas"; o segmento vibração (em verde), com os jornalistas Tiago Leifert, Galvão Bueno e Fernanda Gentil, anunciou as realizações do ano no terreno dos esportes; o segmento diversão (em amarelo), com Fernanda Lima, Pedro Bial, Marcelo Adnet, Leandro Hassum, Ana Maria Braga e Fátima Bernardes, divulgou os programas de entretenimento mais representativos da emissora.

- $\quad$ projeto Luz, Câmera 50 anos

O projeto Luz, câmera 50 anos, parceria entre as áreas de Programação e de Entretenimento, resumiu-se na exibição de 12 longas-metragens elaborados a partir de séries, minisséries e seriados exibidos na televisão entre 1982 e 2014 . Cada telefilme, com duração de 80 a 130 minutos, constituiu uma releitura das obras mais emblemáticas da emissora, com vistas a oferecer ao público sucessos representativos da produção global, ressaltar a memória da teledramaturgia nacional, além de consolidar e expandir a produção da emissora.

\section{- novos lançamentos}

Outra iniciativa de divulgação foi o lançamento de novos programas, como os filmes especiais, as microsséries, a $15^{\text {a }}$ temporada do Big Brother Brasil, o Planeta Extremo, a segunda temporada de ficção científica estadunidense e de novas telenovelas, como a novela das seis (Sete vidas), a das nove (Babilônia), além da reprise de $O$ rei do gado. A divulgação dos novos lançamentos é a maneira de a emissora fortalecer o segmento da teledramaturgia, ressaltar ao público as novidades da grade, diferenciar-se da concorrência e também consolidar a própria posição no cenário nacional.

\section{b. Programa Tá no ar: a TV na TV}

O programa semanal de humor Tá no ar: a TV na TV, escrito e protagonizado por Marcius Melhem e Marcelo Adnet, com direção de núcleo de Maurício Farias, foi criado para ser um programa de humor, exibido às quintas-feiras, em torno de $23 \mathrm{~h}$. No entendimento dos autores, teve como proposta, pautada nos programas e nos atores da emissora, tratar de forma crítica e bem humorada todos os acontecimentos que cercam o fazer televisual (CASTRO, 2014, p. 8), misturando conteúdo temático com intervalo comercial, informação com crítica social, brincadeira com denúncia, gozação com apelação.

Desde o lançamento, o programa estreou em esquema de temporada: a primeira foi de abril a junho de 2014 (com nove episódios); a segunda, de fevereiro a abril de 2015 (com 10 episódios), cuja última emissão foi veiculada em pleno mês de aniversário da emissora, mais precisamente em 16 de abril de 2015.

\footnotetext{
$44 \frac{\text { Comunicação \& Inovação, PPGCOM/USCS }}{\text { v. 17, n. 33 (35-50) jan-abr } 2016}$
} 
Na sua estrutura, o programa combinou pequenas cenas de programas de maior representatividade nas áreas que envolvem informação, emoção, vibração e diversão; paródias de programas já veiculados, com versão divertida de algum episódio e com ambientação no aqui e no agora; referência a ações da concorrência; ênfase na exibição de quadros consagrados, como Galinha preta pintadinha, Jardim urgente e Militante revoltado.

\section{Níveis intra e intertextual}

No que se refere à construção interna e às relações que a emissão mantém com outros textos, podem-se reconhecer estratégias da ordem da inerência (condensação) e da aderência (expansão), assim especificadas:

\section{c. Inerência: ordem da condensação}

- Recuperação de flashes de programas anteriores

A emissão do dia 16 de abril recuperou flashes dos principais programas da emissora como: telejornais, entrevistas (Hebe Camargo e Leda Nagle, entre outros), acontecimentos marcantes no país (informação); telenovelas, seriados, personagens inesquecíveis que marcaram o imaginário do público, representados, entre outros, por Lima Duarte, Regina Duarte e Francisco Cuoco (emoção); fatos esportivos de grande repercussão no país, como, entre outros, o recorde de João do Pulo no atletismo ou a medalha olímpica conquistada por Oscar no basquete (vibração); programas de humor, de auditório e apresentações musicais (diversão).

Os flashes apresentados, sintetizando e reforçando o fazer da emissora nos últimos 50 anos, têm a finalidade de relembrar sucessos anteriores, de impactar o telespectador e de reforçar a trajetória da emissora nos diferentes setores de atuação, além de consolidar sua posição em relação à concorrência.

- criação de paródia a partir de programas já veiculados

A mesma emissão explorou a reapresentação, em forma de paródia, de cenas envolvendo programas da emissora, como as telenovelas Irmãos Coragem e Escrava Isaura e o programa Globo de ouro. As cenas parodiadas reproduzem personagens e cenas da produção original, transportando as situações para os dias de hoje e construindo uma argumentação em torno dessa atualidade, o que desencadeia efeitos de sentido divertidos e inusitados.

- criação de paródia com a concorrência

Outro recurso explorado é a referência divertida a temáticas de outras emissoras, como é o caso da mistura do mundo da televisão com o da religiosidade, combinando termos do universo semântico da igreja (abadia, Nossa Senhora, capelão, altar, 
procissão, entre outros) com nomes e logotipos dos programas da emissora (Bom dia, Brasil, Encontro com Fátima Bernardes, Caldeirão do Huck, Tá no ar, Profissão repórter, entre outros). O resultado é o anúncio da programação de um dia do canal a cabo católico das Organizações Globo: o REZE Globo (Abadia Brasil, Encontro com Nossa Senhora de Fátima, Capelão do Huck, Tá no altar, Procissão repórter, entre outros), fazendo releitura da programação da emissora com as novas denominações, o que acarreta essa mistura de vozes e de universos, com efeitos de sentidos que entrelaçam imprevisibilidade, ludicidade e irreverência. Mais que tudo, a intenção é parodiar programas de conteúdo religioso, tão impregnados na televisão de hoje e uma das características marcantes da concorrência.

\section{- ênfase a quadros temáticos}

$\mathrm{Na}$ construção do programa, três quadros tiveram maior destaque, tendo em vista o tempo de duração do todo: o desenho infantil Galinha preta pintadinha, o telejornal Jardim Urgente e as reiteradas aparições do Militante revoltado.

- Galinha preta pintadinha - o quadro da Galinha preta pintadinha evoca, em primeiro lugar, o desenho infantil Galinha pintadinha, verdadeira unanimidade entre as crianças, e, em segundo, os programas infantis a elas dedicados e, paradoxalmente, quase expulsos da grade nos dias atuais. No programa, a galinha preta pintadinha não apenas é motivo principal de festa infantil (com decoração por todo o cenário), como ganha espaço na televisão para o lançamento de um suposto DVD. Essa duplicidade parece evocar a difícil tarefa de encontrar o tom adequado dos programas infantis, que quase sempre beiram o exagero ou o ridículo.

- Jardim Urgente - o quadro, denominado Jardim Urgente, mostra um apresentador de programa jornalístico bastante empolgado, exaltado, fazendo denúncias ferozes, com apoio da repórter que, in loco, também comprova o mesmo impasse: a recusa da pequena Sofia de entrar no palco para representar seu papel no teatro da creche Pintinho Serelepe. O tom do apresentador é apaixonado e extremamente parcial, em contraponto à banalidade do fato acontecido.

O telejornal, em primeiro lugar, faz uma alusão direta ao programa Brasil Urgente da emissora concorrente, em que o apresentador, com postura semelhante, fala alto, gesticula, denuncia, dirige-se aos telespectadores, mostra sua revolta, manifesta sua inconformidade diante de algum problema, posicionando-se sempre com paixão e emoção na crítica que faz de todas as instâncias de poder no país. Essa postura contrapõe-se, de certa forma, àquela assumida por âncoras e repórteres da Globo, reconhecida pela atitude aparentemente imparcial e comedida de seus profissionais 
de jornalismo. As vozes dos dois universos jornalísticos, diametralmente opostos, expõem as críticas existentes sobre a imparcialidade jornalística e sobre a forma de comportamento do profissional diante dos fatos, convocando o telespectador para um posicionamento efetivo diante dessas situações, além de reforçar o tom apaixonado e, de certa forma, ridicularizar a posição exaltada.

- Militante revoltado - o outro quadro traz um ator de sotaque pernambucano que assume o papel de crítico e faz denúncias contra a Rede Globo, acusando-a de possuir símbolo satanista, de ter relação estreita com o período da ditadura militar e de possuir vínculo com o imperialismo estadunidense, além de enfatizar o quanto ela valoriza seus fazeres e promove suas novelas. São acusações explícitas e diretas que muito se assemelham às posições assumidas por aquelas pessoas que, frequentemente, criticam o poder e a influência exercida pela emissora.

A formulação explícita de uma crítica antecipada funciona, assim, como uma maneira de desqualificar qualquer eventual comentário que a emissora possa sofrer, evitando assim quaisquer apreciações negativas futuras. Tudo que se possa dizer em relação à emissora (como frequentemente o fazem os críticos mais severos) é denunciado e, ao mesmo tempo, banalizado.

Em síntese, no que se refere à inerência, o programa — inspirado em tudo que se faz na televisão - estrutura-se em torno de uma sequência de quadros que parodiam situações extraídas da própria programação eda concorrência, além de remeter aos contumazes críticos da emissora que não poupam palavras para combater o poderio da Globo. Não obstante, os quadros são mostrados sob outra angulação, capaz de provocar impacto, admiração e surpresa, subvertendo a ordem conhecida e habitual, levando o telespectador a manifestar algum tipo de reação diante do inusitado.

\section{d. Aderência: ordem da expansão}

- desdobramento do programa em outras mídias

A expansão em outras mídias compreende jornais, revistas, quadrinhos e internet, ainda que nem sempre haja participação direta da emissora para anunciar ao público as angulações possíveis. Sobretudo em se tratando de telenovelas, essas mídias alimentam-se de informações sobre a repercussão da trama, sobre o resumo do próximo capítulo, sobre o destino dos personagens, além de acontecimentos que cercam a vida pessoal desses atores.

- desdobramento em outros espaços da grade

A expansão, dentro da emissora, diz respeito ao transbordamento do programa em outros espaços da grade, como chamadas, peças comerciais, programas autorreferenciais, 
participação dos atores em outros programas da emissora, sempre para remeter o telespectador ao programa em exibição.

\section{- reiteração do programa no site institucional}

O programa, ao mesmo tempo em que foi exibido na telinha, ganhou espaço em páginas digitais, como o site oficial da emissora (GShow), que também apresentou informações adicionais, desde o chamamento maior, voltado para a gravação ("o que rolou nos bastidores da gravação") ou os diferentes personagens representados por Marcelo Adnet até quadros, relativamente a comentários dos humoristas sobre a experiência junto ao programa, a respostas sobre uma eventual pergunta "quem é o mais louco?", a uma brincadeira do apresentador Bevilácqua sobre o "foca em mim". Cada um desses quadros pode ser desdobrado mediante acesso pelo site.

O site também contém zapeadas, que são acessos possíveis ao "programa", aos "bastidores", ao "militante", à "galinha preta" e ao "jardim urgente", ofertados ao telespectador/internauta, além de remissão às plataformas digitais de redes sociais, Facebook, Twitter, Google+,Instagram.

- releitura da abertura do programa

O programa se inicia com um chamamento, semelhante àquele feito em edições de caráter extraordinário: a tela é ocupada por inteiro com o aviso da interrupção e o locutor em off faz a contagem regressiva. No programa, a mensagem que ilustra a interrupção é: "interrompemos nossa programação pra avisar que este mês a Globo completa 50 anos e por contrato somos obrigados a dar parabéns", complementada pela contagem regressiva do locutor em off. Na aparente configuração de uma notícia extraordinária, o programa visa romper com a expectativa do telespectador e provocar um efeito de surpresa, que se complementa na contagem regressiva das "cinquentonas" da Globo (5- Patrícia Pillar; 4- Maitê Proença; 3- Débora Bloch; 2- Cláudia Ohana; 1- Roberta Close), o que confere irreverência e ludicidade.

Em síntese, no que se refere à aderência e acompanhando a tendência atual, a emissora não apenas abre espaços na grade para expandir o programa, como mantém plataforma institucional, responsável, acima de tudo, pelo transbordamento do programa em ambientes digitais, com informações pontuais e complementares sobre emissão, direção, atores e muito mais que possa sensibilizar e/ou atrair o internauta.

\section{Considerações finais}

A proposta deste estudo foi, a partir da articulação entre mídia televisual, discurso promocional e novas tecnologias, examinar as repercussões e as interferências dos 
avanços tecnológicos na construção do texto televisual de natureza promocional, buscando reconhecer as estratégias empregadas pela produção televisual, seja da ordem da condensação (inerência), seja da ordem da expansão (aderência).

Assim, utilizando como pano de fundo a Rede Globo e a emissão do programa Tá no ar: a TV na TV, do dia 16 de abril de 2015, a ideia é reconhecer os movimentos estratégicos presentes no seu discurso, que reforçam essa fala capitaneada pela emissora.

O programa, em seu todo, assemelha-se a uma revisão bem-humorada da própria televisão, através de um conjunto de quadros que misturam programas da própria emissora, da concorrência e até situações criadas com supostos críticos da emissora. Assim, o programa consegue desnudar discursos, discutir com a sociedade as coisas que estão aí, além de propor uma crítica antecipada a tudo o que nela se faz. É, no fundo, uma grande paródia da própria televisão e, nesse sentido, parece ter atingido sua meta. A emissão analisada não apenas veio marcada de experimentação, novidade e ousadia, como mobilizou toda a empresa, exigindo-lhe redobrada atenção para o êxito do empreendimento.

No detalhamento das estratégias de condensação (inerência) e de expansão (aderência), percebe-se que, principalmente com o advento da televisão digital e das constantes inovações tecnológicas, o discurso televisual vem buscando formas de se adaptar a essas mudanças, sobretudo no movimento de aderência, ao espalhar para outras plataformas informações adicionais que envolvem profissionais, bastidores de gravação e mesmo especulações paralelas. Tudo é feito para acompanhar os novos tempos e buscar estratégias diferenciadas de convocação do público.

Acima de tudo, não se pode negar o caráter inovador que o programa traz, procurando "zoar de tudo" o que se faz em televisão. Mais do que nunca, no programa, a fala de si mesma confere à emissora esse valor de recorrência ao próprio fazer e de convocação do telespectador, que se vê forçado ao envolvimento. Com isso, a intenção é quebrar tabus e explorar fórmulas conhecidas para desmistificá-las. E, nessa medida, a proposta de paródia trazida por Tá no ar: a $T V$ na $T V$ tem humor e faz muita brincadeira com as atrações da emissora.

\section{Referências}

CASTRO, M. Promocional: um percurso convergente entre mundos, mídias e plataformas. In: DUARTE, E.; CASTRO, M. Convergências midiáticas: produção ficcional - RBS TV. Porto Alegre: Sulina, 2010 .

CASTRO, M. Tá no ar: a TV na TV e sua configuração estratégica. In: XXXVII CONGRESSO BRASILEIRO DE CIÊNCIAS DA COMUNICAÇÃO - Intercom, Foz do Iguaçu, PR, 2014. 
DUARTE, E.; CASTRO, M. Produção midiática: o ir e vir entre teoria, metodologia e análise. In: BARICHELLO, E.; RUBLESCKI, A. (orgs.). Pesquisa em comunicação: olhares e abordagens. Santa Maria: Facos-UFSM, 2014. p. 67-87.

DUARTE, E.; CASTRO, M.. Sobre a convergência midiática. In: . Convergências midiáticas: produção ficcional - RBS TV. Porto Alegre: Sulina, 2010.

ECO, U. Tevê: a transparência perdida. In: Viagem na irrealidade cotidiana. Rio de Janeiro: Nova Fronteira, 1984.

JENKINS, H. Cultura da convergência. São Paulo: Aleph, 2009.

JOST, F. Compreender a televisão. Porto Alegre: Sulina, 2010.

MACHADO, A. A televisão levada a sério. 3 ed. São Paulo: Senac, 2003.

MÉDOLA, A. Televisão digital, mídia expandida por linguagens em expansão. In: SQUIRRA, S.; FECHINE, Y. (orgs.). Televisão digital: desafios para a comunicação. Porto Alegre: Sulina, 2009.

PATRIOTA, K. Sob demanda, convergente e interativa: a customização da publicidade na televisão digital. In: SQUIRRA, S.; FECHINE, Y. (orgs.). Televisão digital: desafios para a comunicação. Porto Alegre: Sulina, 2009.

PRIMO, A. Crítica da cultura da convergência: participação ou cooptação? In: DUARTE, E.; CASTRO, M. Convergências midiáticas: produção ficcional - RBS TV. Porto Alegre: Sulina, 2010.

SEMPRINI, A. A marca pós-moderna: poder e fragilidade da marca na sociedade contemporânea. São Paulo: Estação das Letras, 2006.

TÁ NO AR: A TV NA TV. Direção de núcleo: Maurício Farias. Um programa de Marcius Melhem, Marcelo Adnet e Mauricio Farias. Rio de Janeiro: Globo Comunicação e Participações S.A., 2014. Programa de televisão.

WOLTON, D. Elogio do grande público: uma teoria crítica da televisão. São Paulo: Ática, 2006. 